\title{
A Multilevel Examination of Benevolent Leadership and Innovative Behavior in R\&D Contexts: A Social Identity Approach
}

Journal of Leadership \& Organizational Studies 2017, Vol. 24(4) 479-493 (C) The Authors 2017 Reprints and permissions: sagepub.com/journalsPermissions.nav DOI: $10.1177 / 1548051817705810$ journals.sagepub.com/home/jlo (S)SAGE

\author{
Lale Gumusluoglu', Zahide Karakitapoğlu-Aygün', and Terri A. Scandura²
}

\begin{abstract}
Studies of innovation have emphasized the importance of leadership for individual or team innovative behaviors, but have largely ignored cross-team innovative behaviors. Enhancing innovative behaviors across teams is particularly vital for organizations relying on large-scale, complex, and multiteam projects to compete in a dynamic environment. We extend the innovation literature by introducing benevolent leadership as an antecedent to innovative behavior within and across teams. We examine identification to the team and department as mediators based on social identity theory in a sample of 397 R\&D employees (consisting of 68 teams). First, individuals reported that benevolent R\&D leaders facilitate innovative behavior within their teams when employees are highly identified with these teams. Second, on average, teams reported that benevolent R\&D leaders enhance their teams' innovative behavior across the boundaries when these teams are highly identified with the R\&D department. Finally, in contrast to social identity theory's expectations, individuals reported that benevolent R\&D leaders facilitate their innovative behaviors with other teams when employees are highly identified with their teams. The theoretical and practical implications of our findings along with suggestions for future research are discussed.
\end{abstract}

\section{Keywords}

benevolent leadership, team identification, department identification, team innovative behavior, cross-team innovative behavior, social identity theory

Organizations adopt different strategies to foster creative and innovative behavior for competitive advantage and survival. This is particularly important for those that rely on large-scale projects which require teams to appreciate and utilize distinctive knowledge both within and across teams (Glynn, Kazanjian, \& Drazin, 2010; Hoegl, Weinkauf, \& Gemuenden, 2004; S. K. Markham \& Lee, 2014; Scott \& Bruce, 1994; Taggar, 2002). However, studies of innovation have mostly focused on individual or intrateam innovative behavior while ignoring cross-team innovative behavior (Anderson, Potocnik, \& Zhou, 2014; Gong, Huang, \& Farh, 2009). To achieve such innovation, leadership is needed to enhance the innovative capabilities of teams through coordination of their expertise and collective actions (Amason, Thompson, Hochwarter, \& Harrison, 1995; Gong et al., 2009; Gupta \& Singh, 2015; Norrgren \& Schaller, 1999; Scott \& Bruce, 1994). The current study extends prior research by examining how leadership, particularly the benevolent aspect of paternalistic leadership, contributes to innovative behavior within and across teams, both of which are extremely important in R\&D contexts. More specifically, based on social identity theory, we propose that leaders foster team and cross-team innovative behavior through building strong team and department identification, respectively.

Despite findings that leadership is related to innovation (Eisenbeiss, van Knippenberg, \& Boerner, 2008; Gumusluoglu \& Ilsev, 2009; Keller, 2006; Somech, 2006), there is a paucity of research examining the leadershipinnovation link in different cultural contexts. Western contexts have been characterized as individualistic and low power distance (Hofstede, 1980). In particular, there is a need to investigate the effects of leadership on innovation in countries characterized by collectivism and high power distance, such as Turkey, where the expectations and values of followers are different than those in an individualistic Western context, where most research has been conducted. Indeed, one of the most prevalent and effective leadership styles in cultures of Asia, the Middle East and Latin America is paternalistic leadership (Aycan, Schyns, Sun, Felfe, \&

\footnotetext{
'Bilkent University, Ankara, Turkey

${ }^{2}$ University of Miami, Miami, FL, USA
}

\section{Corresponding Author:}

Lale Gumusluoglu, Faculty of Business Administration, Bilkent University, 06800 Bilkent, Ankara, Turkey.

Email: tomruk@bilkent.edu.tr 
Saher, 2013; Pellegrini \& Scandura, 2008). Paternalism, consisting of authoritarianism, benevolence, and morality (Farh \& Cheng, 2000), suggests that people in authority provide protection to those under their care in exchange for loyalty and deference (Aycan, 2001, 2006).

While research has proposed three dimensions of paternalistic leadership, especially one dimension, benevolent leadership (BL), has been consistently and positively related to workplace outcomes such as organizational commitment, loyalty, and trust in leaders (Karakas \& Sarigollu, 2012; Pellegrini \& Scandura, 2006, 2008). BL may also have positive effects on innovative behavior. For example, research suggests that under benevolent leaders, subordinates feel exemplary and valuable (Wang \& Cheng, 2010), and experience high levels of comfort and interpersonal trust which may facilitate innovative behavior (Farh \& Cheng, 2000; Mumford \& Gustafson, 1988). A recent qualitative study of R\&D workers shows that the strongest attribute of changeand innovation-oriented leadership in the Turkish R\&D context is BL (Karakitapoğlu-Aygün \& Gumusluoglu, 2013b). We extend this line of research and posit that BL may also be an appropriate style for enhancing innovative behavior on a larger scale, namely, team and cross-team innovative behavior.

Benevolent leaders not only directly motivate their subordinates but also foster a family feeling among them and increase their identification to both their teams and departments which in turn facilitates collaboration within and across teams. Since such collaborative and team efforts toward innovation are more common in R\&D settings, we focus on R\&D leaders and employees in the present study. We specifically focused on department leaders since team leaders tend to act as project supervisors handling daily tasks in the Turkish context (Avc1 \& Topaloğlu, 2009). In Turkey, team leaders are typically one of the team members and are not perceived as a formal leader, but rather as a colleague. These lower level team leaders have expertise in the technical area of the project and serve more in a technical advisory role than a leadership role (Waldman \& Atwater, 1994). Instead, the formal position power belongs to R\&D department managers who have the authority to hire, evaluate, and reward team members, and make critical decisions for them as well.

We suggest that benevolent R\&D department leaders facilitate team and cross-team innovative behaviors through different identification foci. We mainly propose that benevolent department leaders will enhance: (a) team innovative behavior through team identification and (b) cross-team innovative behavior through building department identification. In addition to these major hypotheses, we also examine whether team identification will negatively mediate the relationship between $\mathrm{BL}$ and cross-team innovative behavior based on recent discussions of threat in social identity theory (Bartel, 2001; Glynn et al., 2010).
The contributions of this study are threefold. First, we contribute to the paternalistic leadership literature by examining the effects of BL on innovative behavior. Given the lack of studies examining this link, our study sheds light on the psychological processes underlying the effects of leadership on innovative behavior by proposing identification with the team and department as potential mediators. Second, we focus on different foci of innovative behavior. Our study specifically extends the team innovation literature by differentiating between team and cross-team innovative behavior both of which are critical in innovative R\&D settings. In addition, our study contributes to the recent discussions on the potential for negative effects of team identification on cross-team innovative behavior in multiteam contexts.

\section{Literature Review and Hypotheses}

\section{Paternalistic Leadership}

Paternalistic leadership has been defined as a leadership style that combines discipline, authority, and power with fatherly benevolence (Cheng, Chou, Wu, Huang, \& Farh, 2004; Farh \& Cheng, 2000). Farh and Cheng (2000) describe paternalistic leadership as consisting of three dimensions: authoritarianism, benevolence, and morality. Authoritarianism refers to leader behaviors that assert authority and control, and demand unquestioning obedience from subordinates. Benevolence refers to leader behaviors that demonstrate individualized, holistic concern for subordinates' personal and familial well-being. Morality refers to leader behaviors that demonstrate superior moral character and integrity through acting unselfishly and leading by example. Previous research found that benevolence and morality dimensions showed positive relationships with many subordinate outcomes, whereas authoritarianism was found to be negatively related to those outcomes (for a review, see Pellegrini \& Scandura, 2008). These results suggest that dimensions of paternalistic leadership should be used separately to predict different and relevant outcomes (Farh, Cheng, Chou, \& Chu, 2006).

\section{Benevolent Leadership and Innovative Behavior}

We focused on benevolence dimension of paternalism in the present study for the reasons explained below. The traditional business context in Turkey has been defined as relatively collectivistic and high in power distance (Aycan, Kanungo, Mendonce, Kaicheng, \& Deller, 2000). Congruent with these cultural values, BL is a prevalent management style in the Turkish context (Erben \& Güneşer, 2008) where employees tend to form and maintain close relationships with their leaders. Leaders are expected to support, care for, and protect their employees. They serve as father figures 
and show concern for their subordinates' personal and family problems. Consistent with this parental style, these leaders try to get to know each employee, are interested in all aspects of their employees' lives and participate in their special days (birthdays, weddings, funerals, etc.). These paternalistic leadership features in Turkey are in line with S. E. Markham's (2012) analysis of the evolution of leadership. He argues that in tribal-based societies that are similar to the ancient family where a strict social hierarchy exists, paternalistic leadership is a more prevalent style as compared with consultative or participatory leadership styles observed in modern organizations. In socially stratified societies, long-term preservation and enhancement of one's extended family is critical where father of the family is expected to play a variety of centralized roles such as being the father of the clan, the economic decision maker, arbiter of justice, and a military head as examples. Indeed, in Turkish folklore, "Devlet Baba" means "Papa State" representing a father-son relationship between citizens and the state. It might be argued that in Turkey, the shift from traditional, close-knit communities to a modern, commercial society based on impersonal, contractual relations has not yet been achieved where both tradition and modernity have coexisted (Sözen \& Shaw, 2003).

Supporting the aforementioned cultural and societal context conducive to paternalistic leadership, KarakitapoğluAygün and Gumusluoglu (2013b) found that the strongest emergent attribute of change-oriented leadership in the Turkish R\&D context was BL. In line with the strong relationship orientation in Turkey, even change-oriented leaders were expected to act like father figures, and $R \& D$ workers wanted to form and maintain close and harmonious relationships with these leaders. In a follow-up quantitative study with R\&D workers in the Turkish context, BL showed significant positive associations with commitment to and identification with the R\&D department (Karakitapoğlu-Aygün $\&$ Gumusluoglu, 2013a). These findings overall imply that showing care and concern for employee well-being, and creating a family environment are conducive to the effective management of knowledge workers (Norrgren \& Schaller, 1999). Indeed, S. K. Markham and Lee (2014) reported that we-ness or family-like relationships in new product development teams increased knowledge sharing within and across teams. The present study extends these findings and focuses on how benevolent leaders facilitate team and crossteam innovative behaviors in R\&D settings.

In spite of the many positive outcomes of BL identified in the literature (Pellegrini \& Scandura, 2008), its link with innovative behavior has not yet been studied. Only Wang and Cheng (2010) found a strong positive relationship between BL and creativity when either creative role identity or job autonomy is high. However, they examined individual creativity, yet ignored the team-level outcomes which are highly valued in today's complex, multiteam-based organizations. Leaders play an important role in shaping affective processes, creating a cooperative atmosphere and inducing collaboration both within and between teams in such complex R\&D organizations. Thus, more research is needed to establish the relationship between BL and innovative behavior of teams.

Innovative behavior is the intentional introduction and application of new ideas, products, processes and procedures to work roles, units, or organizations (West \& Farr, 1989). Accordingly, team innovative behavior refers to generation and implementation of ideas for new and improved products, processes, services, or ways of working (West, 2002). In many cases, however, it is common for teams to work together to produce larger innovative products especially in settings where complex and multiteam projects are common (Glynn et al., 2010; Hoegl et al., 2004). Based on this reasoning, we define cross-team innovative behavior as the extent to which a team works with other teams to facilitate the development and implementation of new innovations. In other words, cross-team innovative behavior involves exchange of resources, cooperation, and coordination with other teams to implement solutions to problems (e.g., staff or time shortages, etc.), as well as channeling ideas developed by the team into innovations and implementing new practices across the organization (e.g., coordinating cross-team activities, assignment of organizational duties).

\section{The Mediating Roles of Team and Department Identification}

We rely on social identity theory (Ashforth \& Mael, 1989; Tajfel \& Turner, 1986) to explain the mediating roles of team and department identification in BL-innovative behavior link. Ashforth and Mael (1989) define social identification as the perception of oneness with or belongingness to an entity. A person who identifies with a group perceives himself or herself as psychologically intertwined with the fate of that entity, and experiences the successes and failures of the group as personal successes and failures. Social identification has both motivational and behavioral consequences. For example, a high level of identification causes individuals to engage in behaviors that are congruent with their identity and express that identity. Similarly, identification with a collective increases the importance of the collective outcomes for the individual and thus the desire to make a contribution toward the achievement of such outcomes (Shamir, Zakay, Breinin, \& Popper, 2000).

The question of how benevolent leaders create high levels of team and department identification where members work collaboratively for the same collective target has yet to be addressed in the literature. One unique characteristic of such leaders is that they create a family environment in their units behaving like a father figure toward their employees (Aycan, 2006). They invest both positional and personal 
resources for the welfare of their followers. The emotional bond between the leader and their followers evokes loyalty and long-term commitment to the team, unit and/or organization (Cheng et al., 2004; Pellegrini, Scandura, \& Jayaraman, 2010). Since those leaders behave like a senior family member and feel responsible for subordinates, followers feel that they are part of the family, consequently have higher levels of identification with their teams and departments. Similarly, Shamir et al. (2000) argue that leaders can increase followers' identification with their units through creating an inclusive atmosphere. When leaders show support and consideration for members' needs, and attend to aspects of the relationships, followers are more likely to identify with their groups and units. As the representatives and symbols of their units, a leader's inclusive behaviors create a sense of "we" both at the team and department levels.

Team identification as a social identity may be particularly important to team innovative behaviors. Oneness with and belongingness to the team may cause team members to internalize the team's objectives as their own since they feel psychologically intertwined with the fate of the group. When members are identified with their teams, they put the team before the self and focus on shared goals (B. van Knippenberg, van Knippenberg, De Cremer, \& Hogg, 2004). Identification with a group motivates behavior that is perceived as consistent with that group's identity (Ellemers, de Gilder, \& Haslam, 2004). Hence, members internalize the teams' goals which results in working more toward achieving them (Hirst, van Dick, \& van Knippenberg, 2009). Supporting these contentions, S. K. Markham and Lee (2014) argued that we-ness within a team increases the amount and depth of information, and understanding shared among members in new product development teams. However, identification with the team may not always promote innovative behavior. Identification may be expected to be positively related to work motivation if performance standards are clear and high performance is perceived to be in the collective's interest (D. van Knippenberg, 2000). In $R \& D$ contexts, innovative behavior is integral to team performance, and high-performance expectations and innovative goals are culturally embedded within teams. A strong team identity might therefore be expected to exert a positive influence on team innovative behavior in such contexts (Mascitelli, 2000). Indeed, the effect of team identity on team innovative behavior has been shown to range from a null effect to a positive effect and thus, the average across many studies is likely to be a positive one (Hülsheger, Anderson, \& Salgado, 2009). Thus, we propose the following hypothesis:

Hypothesis 1: BL will positively influence team innovative behavior through the mediating role of team identification.
Considered separately from team identification, department identification represents an attachment to a broader unit (R\&D) consisting of many teams. Benevolent leaders can create such identification by emphasizing department's goals in their units. Department objectives may well serve as superordinate goals which are defined as those " . . that have a compelling appeal for members of each group but that neither group can achieve without participation of the other" (Sherif, 1966, p. 89). Superordinate goals act as a social glue that bonds teams together and facilitate a shared understanding among them. One consequence of social identification is that a shared sense of oneness ensuing from strong department identification may lead teams to perceive the other teams as similar to them. Those teams who perceive unity with the other teams are more likely to communicate their views to others authentically and consistently, and to find ways to more reliably bridge team boundaries and reduce barriers to innovation (Boland \& Tenkasi, 1995). When this occurs, new perspectives and alternative ideas are more likely to enter the team, information is willingly exchanged and innovative ideas are more likely to be discussed with other teams (Hoegl et al., 2004). This argument is supported by research conducted by Kane, Argote, and Levine (2005), which found that experiencing a shared superordinate social identity increased the likelihood of knowledge transfer between groups. When teams share a superordinate identity, they can make effective use of each other's innovative ideas, work effectively together to implement new innovation practices across the teams and help one another if resources are needed to facilitate the implementation of new innovations. As a result, high-quality decisions and solutions are created and implemented collectively fostering cross-team innovative behavior. Therefore, we propose the following hypothesis:

Hypothesis 2: BL will positively influence cross-team innovative behavior through the mediating role of department identification.

While research on social identity and group behavior typically suggests that team identity may result in positive outcomes in terms of within-team processes, it may also have negative consequences in interteam contexts (for a review, see Hewstone, Rubin, \& Willis, 2002). Yet prior empirical research has not examined the effects of social identity on innovative behavior across teams. When there is a high identification within a team, members may increasingly define themselves according to their own group membership and tend to engage in social comparisons with other groups to protect their identity and competitiveness. In such conditions, they may perceive the other group as a threat and be more concerned with prevention, safety, and security to achieve stability within their teams (Bartel, 2001). Such egocentric and self-defensive goals to affirm the integrity of 
the team, may result in a failure to see the broader needs to collaborate with others, discouraging cross-team innovation. Then, teams become more conservative in terms of both the frequency and scope of interactions with other teams where they neither exchange information nor create strategies for solving problems across boundaries (Bartel, 2001). When this happens, their attention shifts to defending the team identity rather than engaging in collaborative work, especially when they are competing with other teams for status, resources, and autonomy as is the case in the $R \& D$ context in the present study. The introduction of novelty and therefore risk to a team's routines and other established aspects of its identity might be seen as threats, and therefore team identity might fail to enhance innovative behavior that crosses the team boundary (Glynn et al., 2010). Thus, we propose the following hypothesis:

Hypothesis 3: Team identification will negatively mediate the relationship between BL and cross-team innovative behavior.

We expect our hypotheses to hold at the team level since we are mainly interested in team and cross-team innovative behaviors. Based on the recent research which underscores the importance of levels of analysis issue (S. E. Markham \& Halverson, 2002; S. E. Markham, Smith, Markham, \& Braekkan, 2014; Schriesheim, Cogliser, \& Neider, 1995), we test to see whether whole team effects are observed in these proposed relationships.

\section{Method}

\section{Sample}

The sample includes 397 (305 male, 92 female) R\&D workers employed by nine Turkish technology companies conducting R\&D activities that are well-known internationally for their innovation efforts. These firms mainly conduct $\mathrm{R} \& \mathrm{D}$ activities in the defense sector, particularly in areas such as information and communication technologies, software development, electronics, and aerospace. We collected data from R\&D teams. We excluded teams with less than three participants from further analysis. The final sample was composed of 68 teams. The average team size was 8.5 members and the average number of respondents per team was 5.84 . The average tenure with the department leader is 1.82 years $(S D=1.89)$. The average age of respondents is 30 years $(S D=6.01)$. In this sample, $88.9 \%$ have university or postgraduate degrees.

\section{Procedure and Measures}

We first contacted senior managers of the firms to obtain their permission for the study. Next, we contacted R\&D or
HR managers of the companies that agreed to participate. They provided us with the names of the R\&D personnel and their leaders, and the members of the teams. On each survey, we used codes for employees and team leaders, and the data were matched. The surveys were distributed in envelopes to assure confidentiality. The overall response rate was $67 \%$. Respondents completed the surveys in their offices and members of the research team collected them. All items in the questionnaire were translated, back-translated, and checked for wording, accuracy, and clarity (Brislin, 1981).

Benevolent Leadership. BL was measured using eight items from Aycan (2006; Aycan et al., 2013) which represent benevolence component of paternalism. Team members were asked to judge the BL behaviors of their department leaders on a scale of 1 (not at all) to 5 (always). Sample items included "Creates a family environment in the workplace," "Behaves like a family member towards his/her employees," "Provides advice to employees like a senior family member," "Attends special events of employees (weddings and funeral ceremonies, graduations, etc.)."

Team and Department Identification. We measured identification with the team and R\&D department using a four-item scale adapted from Doosje, Ellemers, and Spears (1995). Example items are the following: "I feel strong ties with members of this team/department," "I identify with other members of my team/department," and "I view the success of my team/department as my own success." Team members responded on a 5-point response scale ranging from 1 (strongly disagree) to 5 (strongly agree).

Team Innovative Behavior. Team innovation was measured by four items adapted from De Dreu (2006) and one item from Janssen (2000) to fit the technology intensive context ("Team members often implemented new ideas to improve the quality of our products and services," "This team gave a lot of consideration to new and alternative methods and procedures for doing their work," "Team members often produced new services, methods, or procedures," "This was an innovative team," and "This team created new ideas for difficult issues"). Participants responded on a 5-point response scale ranging from 1 (not at all) to 5 (very). We collected data from both team members and team leaders, and created a composite score since we were interested in the perceptions of both leaders and members. This technique is frequently used in research on leadership due to the interest in shared perceptional agreement (Chan, 1998).

Cross-Team Innovative Behavior. This was measured on a five-item scale adapted from Richter, Scully, \& West (2005; e.g., To what extent did both R\&D teams ... "work effectively together in order to enhance organizational innovation?", "make effective use of each other's innovative 
Table I. Descriptive Statistics for the Main Study Variables $(N=397)$.

\begin{tabular}{|c|c|c|c|c|c|c|c|c|c|c|}
\hline & & $M$ & $S D$ & 1 & 2 & 3 & 4 & 5 & 6 & 7 \\
\hline I. & BL (self) & 3.39 & 0.91 & $(.95)$ & & & & & & \\
\hline 2. & TI (self) & 3.77 & 0.74 & $.40 * * *$ & (.89) & & & & & \\
\hline 3. & DI (self) & 3.78 & 0.77 & $.48 * * *$ & $.64 * * *$ & $(.86)$ & & & & \\
\hline 4. & TIB (self) & 3.67 & 0.85 & $.36 * * *$ & $.43 * * *$ & $.49 * * *$ & $(.93)$ & & & \\
\hline 5. & CTIB (self) & 2.95 & 0.92 & $.35 * * *$ & $.29 * * *$ & $.40 * * *$ & $.36 * * *$ & $(.94)$ & & \\
\hline 6. & TIB (leader) & 3.65 & 0.65 & $.15^{* *}$ & .07 & $.13^{*}$ & $.18 * *$ & .09 & $(.89)$ & \\
\hline 7. & CTIB (leader) & 2.86 & 0.78 & $.18^{* *}$ & $.21 * * *$ & $.12 *$ & .09 & $.18^{* *}$ & $.27 * * *$ & (.9l) \\
\hline
\end{tabular}

Note. $\mathrm{BL}=$ benevolent leadership; $\mathrm{TI}=$ team identification; $\mathrm{DI}=$ department identification; $\mathrm{TIB}=$ team innovative behavior; $\mathrm{CTIB}=\mathrm{cross}$-team innovative behavior. Reliabilities are reported in parentheses.

$*_{p}<.05$. **p $<.01$. ***p $<.001$.

ideas?", and "work effectively together in order to implement new innovation practices across the organization (e.g., coordinating cross-team activities, assignment of organizational duties etc.)?" Respondents were instructed to consider the other R\&D team with which their team has collaborated the most but at the same time to some extent competed for resources in the past 12 months when completing the scale. Participants responded on a 5-point response scale ranging from 1 (not at all) to 5 (very). Research assistants in the companies were in contact with the team leaders and members, and requested information regarding the target team to assure that everyone in the team referenced the same target team when rating cross-team innovative behavior. As in the case with team innovative behavior, we collected data from both team members and team leaders, and created a composite score for cross-team innovative behavior.

Control Variables. Past research has identified several demographic variables, such as age, education, and tenure as potential influences on innovative behavior (Mumford, Scott, Gaddis, \& Strange, 2002). Participants in the current study were asked about their age, gender, and tenure with the leader.

\section{Results}

Means, standard deviations, reliability estimates (alphas), and total correlations between study variables are shown in Table 1. We checked the correlations between control variables and the main study variables. Since none of them showed significant correlations, they were not included in subsequent analyses. Then, to examine construct distinctiveness of our measures, we performed confirmatory factor analysis using LISREL (Jöreskog \& Sörbom, 1993) to test competing models. For the items rated by team members, we first tested a single-factor model combining BL, team, and department identification as well as team and crossteam innovative behavior. This model exhibited poor fit as anticipated, $\chi^{2}(296)=7794.56 ; p<.01$; comparative fit index $[\mathrm{CFI}]=.76$; nonnormed fit index $[\mathrm{NNFI}]=.73$; standardized root mean square residual $[\mathrm{SRMR}]=.16$. Then, we tested a three-factor model where we combined teamand cross-team innovative behavior items into the first factor, team, and department identification items into the second factor and BL items into the third factor. This threefactor model again yielded a poor fit, $\chi^{2}(293)=3941.40 ; p$ $<.01 ; \mathrm{CFI}=.86 ; \mathrm{NNFI}=.84 ; \mathrm{SRMR}=.15$ ). Finally, we tested all of our constructs as five separate variables. This five-factor model yielded the best fit, $\chi^{2}(286)=1136.81 ; p$ $<.01 ; \mathrm{CFI}=.95 ; \mathrm{NNFI}=.95 ; \mathrm{SRMR}=.05$. We also tested competing models of the items rated by team leaders. The first model combined team innovative behavior with crossteam innovative behavior and exhibited poor fit, $\chi^{2}(33)=$ $147.72 ; p<.001 ; \mathrm{CFI}=.81 ; \mathrm{NNFI}=.74 ; \mathrm{SRMR}=.22)$. $\mathrm{A}$ model testing these as separate factors fit the data acceptably, $\chi^{2}(32)=61.10 ; p<.01 ; \mathrm{CFI}=.93 ; \mathrm{NNFI}=.90 ; \mathrm{SRMR}$ $=.08$. Overall, we concluded that our measures were appropriate.

Next, we checked to determine whether it is appropriate to aggregate study variables to the team level since we are interested in team and cross-team innovative behaviors for our hypotheses and expected the mediation effects to hold at the team level. Therefore, we calculated the $r_{w g(j)}$ statistics. We found the mean $r_{w g(j)}$ of .92 for team identification, .88 for BL, .79 for department identification, .98 and .79 for team and cross-team innovative behavior, respectively. These values were above the .70 cutoff proposed by James, Demaree, and Wolf (1993). To measure interrater reliability, we computed intraclass correlation coefficients ICC(1) and ICC(2) with values of .40 and .62 for BL, .30 and .53 for team identification, .39 and .67 for department identification, .60 and .87 for team innovative behavior and .66 and .89 for cross-team innovative behavior, which are within acceptable limits for applied samples (Bliese, 2000).

However, Schriesheim et al. (1995) reported some weaknesses in the rwg measure and emphasized the necessity of conducting a more conservative within and between group analysis (WABA) approach in aggregation decisions. Therefore, we used WABA to examine whether it 
Table 2. The Results of WABA Analyses.

\begin{tabular}{|c|c|c|c|c|c|c|c|c|c|c|}
\hline & \multicolumn{5}{|c|}{ WABA I: Variation source } & \multicolumn{5}{|c|}{ WABA II: Covariation source } \\
\hline & \multicolumn{2}{|c|}{$\eta$} & \multicolumn{3}{|c|}{ Ratio } & \multicolumn{2}{|c|}{ Correlation } & \multicolumn{3}{|c|}{ Ratio } \\
\hline & Btw & With & $\eta^{2}$ & $E$ & $\mathrm{~F}$ & $\mathrm{Btw}^{\mathrm{a}}$ & With $^{\mathrm{b}}$ & A & Z & Inference \\
\hline I. BL (self) & .62 & .78 & .39 & 0.79 & $3.08 * * *$ & & & & & \\
\hline$B L \times T I B($ self $)$ & & & & & & $.39 * * *$ & $.33^{* * *}$ & 0.06 & 0.46 & Equivocal \\
\hline BL $\times$ TIB (leader) & & & & & & $.26^{*}$ & -.10 & 0.16 & 1.2 & Equivocal \\
\hline $\mathrm{BL} \times \mathrm{TI}$ & & & & & & $.43 * * *$ & $.37 * * *$ & 0.07 & 0.56 & Equivocal \\
\hline $\mathrm{BL} \times \mathrm{DI}$ & & & & & & $.57 * * *$ & $.42 * * *$ & 0.17 & 1.45 & Moderate wholes \\
\hline$B L \times C T I B($ self $)$ & & & & & & $.44 * * *$ & $.27 * * *$ & 0.17 & 1.37 & Moderate wholes \\
\hline BL $\times$ CTIB (leader) & & & & & & $.28^{*}$ & .05 & 0.23 & $1.74 *$ & Moderate wholes \\
\hline 2. $\mathrm{TI}$ (self) & .55 & .83 & .30 & 0.66 & $2.15 * * *$ & & & & & \\
\hline $\mathrm{TI} \times \mathrm{TIB}$ (self) & & & & & & $.38 * *$ & $.45^{* * *}$ & -0.07 & -0.56 & Equivocal \\
\hline TI × TIB (leader) & & & & & & .15 & $-.11 *$ & 0.04 & 0.30 & Equivocal \\
\hline $\mathrm{TI} \times \mathrm{CTIB}$ (self) & & & & & & $.24^{*}$ & $.29 * * *$ & -0.05 & -0.40 & Equivocal \\
\hline TI × CTIB (leader) & & & & & & $.36 * *$ & .08 & 0.29 & $2.20 *$ & Wholes \\
\hline 3. DI (self) & .50 & .87 & .25 & 0.58 & $1.62 * *$ & & & & & \\
\hline DI × CTIB (self) & & & & & & $.42 * * *$ & $.36 * * *$ & 0.06 & 0.48 & Equivocal \\
\hline DI × CTIB (leader) & & & & & & .23 & .01 & 0.23 & $1.67^{*}$ & Moderate wholes \\
\hline 4. TIB (self) & .52 & .85 & .28 & 0.61 & $1.87 * * *$ & & & & & \\
\hline TIB (self) × TIB (leader) & & & & & & $.35^{* *}$ & .00 & 0.35 & $2.67 * *$ & Wholes \\
\hline 5. CTIB (self) & .55 & .83 & .33 & 0.66 & $2.26 * * *$ & & & & & \\
\hline CTIB (self) $\times$ CTIB (leader) & & & & & & $.31^{* *}$ & .01 & 0.30 & $2.23^{*}$ & Wholes \\
\hline
\end{tabular}

Note. WABA = within and between group analysis; Btw = between group; With = within group; $\mathrm{BL}=$ benevolent leadership; $\mathrm{TI}=$ team identification; $\mathrm{DI}=$ department identification; TIB = team innovative behavior; CTIB = cross-team innovative behavior. Between-group correlations (weighted averages) are based on $\mathrm{J}=67$; Within-group correlations (residuals) are based on $\mathrm{N}-\mathrm{J}=330$. The $F$ tests are the results of one-way analysis of variance. The degrees of freedom: 67, 329.

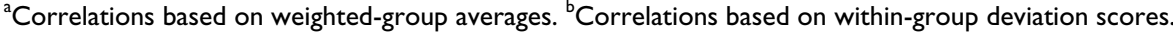

$*_{p}<.05$. **p $<.01$. **** $<.001$.

was appropriate to aggregate our measures to the team level. ${ }^{1}$ We used both the SPSS and DETECT statistical packages (Dansereau \& McConnell, 2000). WABA has been frequently employed by researchers (Dansereau, Cho, \& Yammarino, 2006; S. E. Markham \& Halverson, 2002; S. E. Markham \& McKee, 1995; S. E. Markham et al., 2014). The results of WABA I and WABA II analyses are reported in Table 2 . The traditional $F$ values reported in Table 2 indicate that there is statistically significant between group variation for all of our variables. We also checked for the between- and within-group correlations and the $z$ tests (which determine the significance of the difference in these correlations) for each of the relationships under investigation in this study (S. E. Markham \& Halverson, 2002; Schriesheim et al., 1995). For Hypothesis 1, paternalistic leadership-team identification and team identification-team innovative behavior relationships revealed equivocal effects. Since the within-group correlations were higher than between-group correlations, all of the variables were treated at the individual level for Hypothesis 1. For Hypothesis 2, most of the relationships revealed moderate wholes effects where between-group correlations were higher than within-group correlations.
Therefore, the data were aggregated and Hypothesis 2 was analyzed at the team level. For Hypothesis 3, paternalistic leadership-team identification and team identificationcross-team innovative behavior relationships revealed equivocal effects. Therefore, in the analyses of Hypothesis 3 , all of the variables were treated at the individual level, as is the case for Hypothesis 1.

\section{Hypotheses Tests: Mediation Analyses}

Researchers have been searching for the best statistical test for mediation effect in the past decade. The most commonly used techniques are zero-order and partial correlations, hierarchical regression models, and structural equation modeling. However, recent advances in research methods suggest that nonparametric approaches (e.g., bootstrapping) may offer the best test of the significance of a mediator (Preacher \& Hayes, 2008; Shrout \& Bolger, 2002; Zhao, Lynch, \& Chen, 2010). Indeed, Cheung and Lau (2007) reported that bias-corrected bootstrap confidence intervals (CIs) perform best in testing for mediation effects. Researchers recommend bootstrap methods to be used to assess mediation especially when the sample is small or 
Table 3. Bootstrap Analyses on the Mediating Role of Team Identification in BL-Team Innovative Behavior Link: IndividualLevel Results.

\begin{tabular}{lll}
\hline Bootstrap estimate & $\beta$ & $S E$ \\
\hline Path analysis & & \\
BL-team identification & $.32^{* * *}$ & .04 \\
Team identification-team innovative behavior & $.21^{* * *}$ & .04 \\
Total effect (c) & $.22^{* * *}$ & .03 \\
BL-team innovative behavior (c') & $.16^{* * *}$ & .03 \\
Bootstrapping & $.07 * * *$ & .02 \\
Indirect effect & .0369 & .1006 \\
Bias-corrected 95\% confidence interval & \multicolumn{2}{c}{$.20^{* * *}$} \\
$R^{2}$ & \\
\hline
\end{tabular}

Note. $\mathrm{BL}=$ benevolent leadership; $\mathrm{SE}=$ standard error. $\mathrm{N}=394$. $* * * p<.001$.

moderate. Furthermore, the use of bootstrapping to estimate and test direct and indirect effects can help with mediation problems in which the mediator and outcome variables are not normally distributed. The improvement of bootstrapbased inference over normal-theory approximations is most obvious when one is interested in rejecting the null hypothesis of no indirect effect. Since the core theme of this article is to test the mediating effects of team and department identification, we used this recommended Preacher and Hayes's (2008) bootstrapping procedure $(95 \% \mathrm{CI}$ and 5,000 bootstrap samples) for testing our indirect effects. We utilized Preacher and Hayes's (2008) SPSS macro to estimate the significance of the mediators. If the $95 \%$ CI does not include 0 , then the effect is said to be significant at $p<.05$.

Since we had data from nine different organizations, we included company ID as a control variable in subsequent bootstrapping analyses. We first tested the mediating effects of team identification on BL-team innovative behavior relationship at the individual level. The company effect was not significant $(b=-.03, p>.05)$. Yet the results revealed a significant indirect effect of .07 with a $95 \% \mathrm{CI}$ ranging from .0369 to .1006 (Table 3). Accordingly, BL had a significant effect on team identification $(b=.32, p<.001)$ which, in turn, resulted in a positive association with team innovative behavior $(b=.21, p<.001)$. When the mediating effect of team identification is considered, the effect of $\mathrm{BL}$ on team innovative behavior decreased from $\mathrm{c}=.22, p<.001$ to $\mathrm{c}^{\prime}=$ $.16, p<.001$ ), implying a partial mediation. Thus, Hypothesis 1 was supported at the individual level.

We ran the aforementioned bootstrapping procedure also to test the mediating effect of department identification on cross-team innovative behavior. Based on our WABA inferences, the data were aggregated to the team level for this hypothesis. Consistent with the previous analysis, the control variable had no significant effect on the model $(b=$ $-.00, p>.05)$. The results revealed a significant indirect effect of .12 with a $95 \%$ CI ranging from .0180 to .2767 ,
Table 4. Bootstrap Analyses on the Mediating Role of Department Identification in BL-Cross-Team Innovative Behavior Link: Team-Level Results.

\begin{tabular}{|c|c|c|}
\hline Bootstrap estimate & $\beta$ & SE \\
\hline \multicolumn{3}{|l|}{ Path analysis } \\
\hline BL-department identification & $.32 * * *$ & .07 \\
\hline $\begin{array}{l}\text { Department identification-cross-team } \\
\text { innovative behavior }\end{array}$ & $.39 *$ & .19 \\
\hline Total effect $(c)$ & $.44 * * *$ & .10 \\
\hline BL-cross-team innovative behavior (c') & $.31 * *$ & .12 \\
\hline \multicolumn{3}{|l|}{ Bootstrapping } \\
\hline Indirect effect & $.12 *$ & .06 \\
\hline Bias-corrected $95 \%$ confidence interval & .0180 & .2767 \\
\hline$R^{2}$ & \multicolumn{2}{|c|}{$.26 * * *$} \\
\hline
\end{tabular}

Note. $\mathrm{BL}=$ benevolent leadership; $\mathrm{SE}=$ standard error. $\mathrm{J}=68$.

$* p<.05 . * * p<.01 . * * * p<.001$.

Table 5. Bootstrap Analyses on the Mediating Role of Team Identification in BL-Cross-Team Innovative Behavior Link: Individual-Level Results.

\begin{tabular}{|c|c|c|}
\hline Bootstrap estimate & $\beta$ & SE \\
\hline \multicolumn{3}{|l|}{ Path analysis } \\
\hline BL-team identification & $.32 * * *$ & .04 \\
\hline $\begin{array}{l}\text { Team identification-cross-team } \\
\text { innovative behavior }\end{array}$ & $.19 * * *$ & .05 \\
\hline Total effect $(c)$ & $.24 * * *$ & .04 \\
\hline BL-cross-team innovative behavior (c') & $.18 * * *$ & .04 \\
\hline \multicolumn{3}{|l|}{ Bootstrapping } \\
\hline Indirect effect & $.06 * * *$ & .02 \\
\hline Bias-corrected $95 \%$ confidence interval & .0249 & .1008 \\
\hline$R^{2}$ & \multicolumn{2}{|c|}{$.14^{* * *}$} \\
\hline
\end{tabular}

Note. $\mathrm{BL}=$ benevolent leadership; $S E=$ standard error. $\mathrm{N}=394$. $* * * p<.001$.

where the zero point was not included in the interval (Table 4). Paralleling the aforementioned results, BL had a significant effect on department identification $(b=.32, p<.001)$ which, in turn, resulted in a positive association with crossteam innovative behavior $(b=.39, p<.05)$ at the team level supporting Hypothesis 2. When the mediating effect of department identification is considered, the effect of BL on cross-team innovative behavior decreased from $\mathrm{c}=.44, p<$ .001 to $\mathrm{c}^{\prime}=.31, p<.001$, but it was still significant, suggesting partial mediation.

Finally, we tested the mediating effect of team identification on cross-team innovative behavior in line with social identity theory's threat hypothesis in interteam contexts. Similar to Hypothesis 1, this hypothesis was tested at the individual level. In contrast to Hypothesis 3, the results revealed a significant positive indirect effect of .06 with a 95\% CI ranging from .0249 to .1008 (Table 5). Accordingly, BL had a significant effect on team identification $(b=.32$, 
Table 6. Summary Table of Hypotheses, Inductions, and Mediation Effects.

\begin{tabular}{|c|c|c|c|c|c|}
\hline Hypothesis no. & $\begin{array}{l}\text { Hypothesis } \\
\text { description }\end{array}$ & Induction & $\begin{array}{l}\text { Proposed nature } \\
\text { of mediation }\end{array}$ & Mediation findings & $\begin{array}{l}\text { Support for the } \\
\text { hypotheses }\end{array}$ \\
\hline Hypothesis I & $\mathrm{BL} \rightarrow \mathrm{TI} \rightarrow \mathrm{TIB}$ & Equivocal & Positive & $\begin{array}{l}\text { Full mediation } \\
\text { (positive) }\end{array}$ & $\begin{array}{l}\text { Supported at the } \\
\text { individual level }\end{array}$ \\
\hline Hypothesis 2 & $\mathrm{BL} \rightarrow \mathrm{DI} \rightarrow \mathrm{CTIB}$ & Moderate wholes & Positive & $\begin{array}{l}\text { Partial mediation } \\
\text { (positive) }\end{array}$ & $\begin{array}{l}\text { Supported at the } \\
\text { team level }\end{array}$ \\
\hline Hypothesis 3 & $\mathrm{BL} \rightarrow \mathrm{TI} \rightarrow \mathrm{CTIB}$ & Equivocal & Negative & $\begin{array}{l}\text { Partial mediation } \\
\text { (positive) }\end{array}$ & $\begin{array}{l}\text { Not supported at the } \\
\text { individual level }\end{array}$ \\
\hline
\end{tabular}

Note. $\mathrm{BL}=$ benevolent leadership; $\mathrm{TI}=$ team identification; $\mathrm{DI}=$ department identification; $\mathrm{TIB}=$ team innovative behavior; $\mathrm{CTIB}=\mathrm{cross}$-team innovative behavior.

$p<.001)$ which, in turn, resulted in a positive association with cross-team innovative behavior $(b=.19, p<.001)$. When the mediating effect of team identification is considered, the effect of BL on cross-team innovative behavior decreased from $\mathrm{c}=.24, p<.001$ to $\mathrm{c}^{\prime}=.18, p<.001$, implying a positive partial mediation as compared with our expectations. Thus, Hypothesis 3 was not supported at the individual level. Table 6 summarizes all of our hypotheses, whether the hypotheses are tested at the individual or team level (inductions) and mediation effects.

\section{Discussion}

Neither the leadership nor the team literature has focused on the relational competencies of leaders needed for setting the stage for innovative behavior (Hogg, van Knippenberg, \& Rast, 2012; Wang \& Cheng, 2010). Hence, the present study contributes to both leadership and team innovation literatures by showing that BL, a prevalent leadership style in Eastern contexts, is an effective leadership in R\&D units where innovative behavior is vital. First, our results illustrate that benevolent leaders, who have high levels of relationship orientation, facilitate innovative behavior both within and across teams. Second, it suggests that identification to the team and department are important explanatory mechanisms for the relationship between BL and innovative behavior. Third, contrary to the threat explanations of the social identity theory, we found positive effects of team identification on cross-team innovative behavior.

\section{Theoretical Implications}

Our first finding is that benevolent leaders increase team innovative behaviors through enhancing the followers' identification with their teams. We identified this mediation effect at the individual level of analysis. This finding is consistent with Hirst et al.'s (2009) study which showed that identification with the team encourages persistence and creative effort when creativity is highly valued since identification encourages members to view task accomplishment as an important end in itself. Moreover, identified members emphasize shared team goals more than individual goals. Since R\&D workers are primarily expected to innovate, identified members work more toward achieving innovative goals. These results imply that strong attachment to a team favors team innovative behavior especially when innovation-related goals are explicit to employees and high innovative performance expectations are perceived to be in the team members' interests in R\&D contexts.

Moreover, the aforementioned finding contradicts the argument that identification with the team may result in a devaluation of novelty if it leads to groupthink where members fail to engage with alternative views (Janis, 1982). It also contradicts previous research which indicated a null effect between identification with the team and innovative performance. The individual-level positive impact of identification with the team on team innovative behavior in the present study might be explained by the nature of $R \& D$ work. R\&D workers typically perform interdependent tasks and function with significant autonomy. Since their performance measures depend on their creative and innovative outputs, they are expected to engage in frequent interaction with their team members, have high level of internal communication and incorporate other members' perspectives (Hirst \& Mann, 2004). Furthermore, benevolent leaders encourage group dynamics to build not only a sense of identity but also a safe environment where members are more likely to feel relaxed and share their diverse and novel ideas with the other team members which is the opposite of groupthink. Groupthink resulting from team identification, in fact, may be more evident in other types of teams which do not require knowledge sharing and interdependence between members such as sales or accounting teams.

In addition to the aforementioned indirect effect, we also found at the individual level of analysis that BL has a direct effect on team innovative behavior. When benevolent leaders create such a safe and caring climate, subordinates feel more valued which increases their feelings of gratitude to the leader (Wang \& Cheng, 2010). With a strong sense of gratitude to the leader, they are likely to exert more time and effort on their tasks, and go above and beyond their job roles to benefit broader organizational goals (Konovsky \& 
Pugh, 1994). Positive reciprocity beliefs provide an explanation for these follower behaviors since it suggests that subordinates are likely to reciprocate beneficial behaviors based on their sense of gratitude, indebtedness, and obligation to repay (Umphress, Bingham, \& Mitchell, 2010). When a leader provides long-term care, protection, and nurturance, the followers tend to have warm feelings, and form an emotional bond and a reciprocal relationship with their leaders to continue that positive cycle. In such a strong affect- and gratitude-based environment, team members are more willing to ask questions, seek help and take risks knowing that mistakes will be tolerated (Edmondson, 1999). Since creative and innovative performance are especially critical for R\&D workers, this group of people are likely to reciprocate positive and caring leader behaviors by contributing more to the team's innovative performance.

Supporting Hypothesis 2, on average teams reported that benevolent leaders increase cross-team innovative behavior through enhancing the followers' identification with their department. Our results showed that this mediation effect holds at the team level. The present study, by introducing department identification as a critical factor for cross-team innovative behavior, makes an important contribution to the interteam literature. Departments are units which bring teams under one umbrella. When teams identify with this higher level, they are more likely to view department goals as their own. Hence, under high levels of identification with the department, interteam activities are more likely to occur due to the teams' acceptance of superordinate goals (Sherif, 1966). This larger, more inclusive identity provides the "why" for cooperation that enables productive and cooperative intergroup behavior (Richter, West, van Dick, \& Dawson, 2006). Under such overarching goals, teams are connected to larger department concerns and are likely to collaborate on common goals. Supporting these arguments, previous research has demonstrated that the existence of such superordinate goals have significant effects on the outcomes of project teams through influencing cross-functional cooperation (Pinto, Pinto, \& Prescott, 1993).

The aforementioned finding implies that when benevolent leaders maintain close relationships with their teams and create a family-like environment at the workplace, they enhance identification with the departments resulting in tightly knit communities (Beatty, 2000, p. 6). They are likely to urge their teams to transcend their interests for the benefit of the $R \& D$ department and remind them that knowledge sharing between teams serve R\&D department's functioning and effectiveness. In line with this, S. K. Markham and Lee (2014), drawing on marriage and family therapy, introduced the concept of we-ness to innovative settings. They argue that a group that accepts and protects each other as a family member tries to assure that all the information to make quality decisions will be fully evaluated. Since the focus on interpersonal bonds is strong in settings with high levels of we-ness, family-like interactions will be more tolerant of contrary opinions allowing minority opinions be heard. Team members are more likely to listen, support, challenge each other, and modify and revisit ideas and decisions. In a similar vein, recent study by $\mathrm{Li}$, Shang, Liu, and Xi (2014) found that affiliation climate (i.e., sense of togetherness, caring, and prosocial behaviors among members) was a strong predictor of knowledge sharing in Chinese organizations. Interestingly, followers were found to be more sensitive to affiliation climate as compared with innovativeness climate when knowledge sharing is a concern.

It is perhaps not surprising that such a work climate which is characterized by caring and sense of togetherness created by benevolent leaders may well enhance innovative behavior across teams since it fits the predominant social values in Turkey. When R\&D teams are highly identified with their departments and hold shared goals, they invest more concerted effort in effective communication and smooth collaboration with other teams. This shared vision serves as a source of energy to integrate efforts and resources within R\&D departments. To this end, benevolent leaders serve as climate engineers for their organizations. They develop and adopt an overriding set of goals for their units in an effort to promote higher levels of interaction and cooperation across teams (Sarros, Cooper, \& Santora, 2008). Such collaborative behavior is vital to the successful implementation of $\mathrm{R} \& \mathrm{D}$ projects and effective performance of organizations as a whole (Slater, 2005; Somech \& DrachZahavy, 2013).

Our results also suggest that BL had a significant direct effect on cross-team innovative behavior. One tentative explanation for this positive direct effect can be that these benevolent R\&D department leaders are effective in orchestrating collective action of their teams. It may be the case that these leaders engage in boundary-spanning activities both across teams and departments. As Bartel (2001) argues, such boundary-spanning leaders may show not only taskbased assistance in assignments but also affiliation behaviors such as helping maintain and improve work relationships, listening to their problems and concerns, as examples. Such boundary-spanning behaviors shown by these benevolent department leaders may include solving resource-related problems (money, new members, equipment, etc.), promoting and talking up the teams to others and/or upper levels, communicating with others and garnering support for their teams. This is consistent with previous research which reported that coordinating activities, discussing problems with others, obtaining feedback and negotiating with others, all benefit innovation (Ancona \& Caldwell, 1992; Drach-Zahavy \& Somech, 2010). Future studies may examine how such interteam boundary activities by benevolent leaders affect cross-team innovation.

Contrary to our third hypothesis, we found a positive mediating effect of team identification in BL-cross-team 
innovative behavior link rather than a negative effect. One possible explanation for the lack of support for this threat hypothesis may be the levels of analysis issue. Since our WABA results do not allow us to test this hypothesis at the team level, we identified this finding at the individual level. It may be the case that strongly identified "teams" are more likely to perceive the other teams as threats which may reduce cross-collaboration. In other words, this threat explanation may hold at the team level, but not at the individual level. Therefore, examining these relationships at the team level in future studies will contribute to the threat proposition in the literature. This positive individual-level mediation effect can also be explained by the sensegiving framework (Maitlis, 2005) in the management literature which is defined as "the process of attempting to influence the sensemaking and meaning construction of others toward a preferred redefinition of organizational reality" (Gioia \& Chittipeddi, 1991, p. 442). That is, leaders' sensegiving affects how followers construct their identities and perceive their organizational context (Ravasi \& Schultz, 2006). Benevolent leaders engage in such sensegiving behaviors that create a family environment at the workplace. For example, they behave like a family member toward their employees, provide advice to employees like a senior family member and attend special events of employees where followers develop a shared understanding of togetherness (S. K. Markham \& Lee, 2014). In such family-like contexts, employees are more likely to share sensitive information and be more tolerant to new ideas. In other words, such a family approach creates and maintains congeniality within the organization which enhances information sharing and mutual understanding rather than a hostile innovation culture where team members perceive other teams as threats. Therefore, even when employees are highly identified with their teams, due to the family context and cooperative approaches rather than competitive settings created by benevolent leaders, they will be willing to cooperate and collaborate with other teams. This family approach by leaders in R\&D settings may be more welcome and effective especially in collectivist societies like Turkey where individual interests are subordinated to group interests. Hence, future research is needed to identify whether there are differences across cultures in how highly identified members perceive other teams in multiteam contexts.

\section{Limitations, Future Research, and Practical Implications}

This study was conducted in R\&D contexts where innovative behavior both within and across teams is a meaningful option. In addition, the participants were R\&D workers who may already have high levels of creative role identity and job autonomy (Wang \& Cheng, 2010), which may enhance their willingness to innovate. Therefore, to examine the generalizability of these findings, future research should investigate the effects of BL in other work contexts and other types of teams. Furthermore, the cross-sectional design does not allow examination of causality. Future longitudinal studies would be valuable to examine the causal relationships between BL, identification, and innovative behavior. The findings of the study also call for replication in other cultural settings where $\mathrm{BL}$ is a predominant leadership style, such as Asian contexts. In light of recent studies which indicate that the paternalistic leadership can be an effective leadership style even in individualistic environments (Pellegrini et al., 2010), future research comparing different cultural settings is also needed. Finally, future researchers may also investigate the additive or interactive effects of other leadership styles such as transformational or authentic leadership (Luthans \& Avolio, 2003) together with BL in predicting innovative behavior. Such research would reveal the unique effects of $\mathrm{BL}$ on innovative behavior, after controlling for the effects of other leadership styles.

Despite these limitations, our findings have several implications for human resource managers and especially for managers of R\&D departments. Our findings first imply that R\&D managers can enhance innovative behavior by exhibiting a supportive and benevolent style of leadership. They should build individualized relationships with their followers and show that they care about their followers' work-life balance. Leaders' concern for followers' personal and familial well-being may be especially critical when companies lack formal family-supportive practices such as policies (e.g., flexible working hours) and benefits (e.g., child care subsidies; Aryee, Chu, Kim, \& Ryu, 2013). Therefore, management training and development programs designed for innovation contexts should also include BL. Such programs may foster how to show personal concern, care, support, and guidance in both work and nonwork domains.

Second, our findings suggest that such leaders can increase innovative behavior through enhancing followers' identification with their teams and teams' identification with their departments. To boost innovative behavior, leaders should emphasize higher degrees of socialization and a family feeling among their followers. In such cases, team members may show greater commitment to cooperative efforts and collective interests. Also, to increase identification, leaders should encourage participation in team and department decisions, and objectives. By being exemplary role models to their employees and creating an affiliative climate in their teams and units, leaders may set the stage for innovative behavior both at the team and cross-team levels. Additionally, creating the perception of a shared superordinate identity is an important strategy for managers to improve knowledge transfer and interteam innovation especially in large-scale, multidisciplinary projects. 


\section{Conclusion}

To respond to the increasing need to develop new products, processes, and breakthrough innovations, organizations are using systems which enhance innovative behavior both within and across teams. The current study extends leadership and innovation literatures by introducing BL as an important consideration and provides an insight into the effectiveness of this leadership style among knowledge workers. Consideration of lower (i.e., individual) as well as higher (i.e., team) levels of analyses in the current study provides a better understanding of the relationships between BL and innovative behavior. Our individual-level results reveal that benevolent leaders foster innovative behavior within teams and our team-level results suggest that these leaders play an important role in enhancing teams' innovative behaviors across the boundaries. Contrary to the expectations of the social identity theory, our individual-level results point to positive effects of identification in predicting innovative behavior across teams. Hence, future studies which examine the threat hypothesis of social identity theory at the team level are warranted. We hope the multilevel findings of the study provide insights into the leadership skills necessary for innovative behavior especially in multiteam contexts.

\section{Declaration of Conflicting Interests}

The author(s) declared no potential conflicts of interest with respect to the research, authorship, and/or publication of this article.

\section{Funding}

The author(s) disclosed receipt of the following financial support for the research, authorship, and/or publication of this article: This work was supported by The Scientific and Technological Research Council of Turkey (TUBITAK). Grant number: 107K439.

\section{Note}

1. We thank an anonymous reviewer for this suggestion.

\section{References}

Amason, A. C., Thompson, K. R., Hochwarter, W. A., \& Harrison, A. W. (1995). Conflict: An important dimension in successful management teams. Organizational Dynamics, 24, 20-35.

Ancona, D. G., \& Caldwell, D. F. (1992). Bridging the boundary: External activity and performance in organizational teams. Administrative Science Quarterly, 37, 634-665.

Anderson, N., Potocnik, K., \& Zhou, J. (2014). Innovation and creativity in organizations: A state-of-the-science review, prospective commentary, and guiding framework. Journal of Management, 40, 1297-1333.

Aryee, S., Chu, C. W. L., Kim, T., \& Ryu, S. (2013). Familysupportive work environment and employee work behaviors: An investigation of mediating mechanisms. Journal of Management, 39, 792-813.
Ashforth, B. E., \& Mael, F. (1989). Social identity theory and the organization. Academy of Management Review, 14, 20-39.

Avcı, U., \& Topaloğlu, C. (2009). The differences in perceptions of leadership behaviors on hierarchical levels: An investigation on hospitality employees. KMU IIBF Journal, $16,1-20$

Aycan, Z. (2001). Human resource management in Turkey: Current issues and future challenges. International Journal of Manpower, 22, 252-260.

Aycan, Z. (2006). Paternalism: Towards conceptual refinement and operationalization. In U. Kim, K. Yang, \& K. K. Hwang (Eds.), Indigenous and cultural psychology: Understanding people in context (pp. 445-466). New York, NY: Springer.

Aycan, Z., Kanungo, R. N., Mendonce, M., Kaicheng, Y., \& Deller, J. (2000). Impact of culture on human resource practices: A 10-country comparison. Applied Psychology: An International Review, 49, 192-221.

Aycan, Z., Schyns, B., Sun, J. M., Felfe, J., \& Saher, N. (2013). Convergence and divergence of paternalistic leadership: A cross-cultural investigation of prototypes. Journal of International Business Studies, 44, 962-969.

Bartel, C. A. (2001). Social comparisons in boundary-spanning work: Effects of community outreach on members' organizational identity and identification. Administrative Science Quarterly, 46, 379-413.

Beatty, B. (2000, September). The paradox of emotion and educational leadership. Paper presented at the British Educational Administration and Management Annual Conference, Bristol, $U K$.

Bliese, P. D. (2000). Within-group agreement, non-independence, and reliability: Implications for data aggregation and analyses. In K. J. Klein \& S. W. J. Kozlowski (Eds.), Multilevel theory, research, and methods in organizations: Foundations, extensions, and new directions (pp. 349-381). San Francisco, CA: Jossey-Bass.

Boland, R. J., \& Tenkasi, R. V. (1995). Perspective making and perspective taking in communities of knowing. Organization Science, 6, 350-372.

Brislin, R. W. (1981). Cross-cultural encounters. New York, NY: Pergamon Press.

Chan, D. (1998). Functional relations among constructs in the same content domain at different levels of analysis: A typology of composition models. Journal of Applied Psychology, $83,234-246$

Cheng, B., Chou, L., Wu, T., Huang, M., \& Farh, J. (2004), Paternalistic leadership and subordinate responses: Establishing a leadership model in Chinese organizations. Asian Journal of Social Psychology, 7, 89-117.

Cheung, G. W, \& Lau, R. S. (2007). Testing mediation and suppression effects of latent variables: Bootstrapping with structural equation models. Organizational Research Methods, 11, 296-325.

Dansereau, F., Cho, J., \& Yammarino, F. J. (2006). Avoiding the "fallacy of the wrong level": A within and between analysis (WABA) approach. Group \& Organization Management, 31, $1-42$.

Dansereau, F., \& McConnell, J. J. (2000). Data entry that tests entity and correlational/causal theories for windows user's manual. Buffalo, NY: Institute for Theory Testing. 
De Dreu, C. K. W. (2006). When too little or too much hurts: Evidence for a curvilinear relationship between task conflict and innovation in teams. Journal of Management, 32, 83-107.

Doosje, B., Ellemers, N., \& Spears, R. (1995). Perceived intragroup variability as a function of team status and identification. Journal of Experimental Social Psychology, 31, 410-436.

Drach-Zahavy, A., \& Somech, A. (2010). From an intrateam to an interteam perspective of effectiveness: The role of interdependence and boundary activities. Small Group Research, 41, 143-174.

Edmondson, A. (1999). Psychological safety and learning behavior in work teams. Administrative Science Quarterly, 44, 350-383.

Eisenbeiss, S. A., van Knippenberg, D., \& Boerner, S. (2008). Transformational leadership and team innovation: Integrating team climate principles. Journal of Applied Psychology, 93, 1438-1446.

Ellemers, N., de Gilder, D., \& Haslam, S. A. (2004). Motivating individuals and groups at work: A social identity perspective on leadership and group performance. Academy of Management Review, 29, 459-478.

Erben, G. S., \& Güneşer, A. B. (2008). The relationship between paternalistic leadership and organizational commitment: Investigating the role of climate regarding ethics. Journal of Business Ethics, 82, 955-968.

Farh, J. L., \& Cheng, B. S. (2000). A cultural analysis of paternalistic leadership in Chinese organizations. In J. T. Li, A. S. Tsui, \& E. Weldon (Eds.), Management and organizations in the Chinese context (pp. 84-127). London, England: MacMillan.

Farh, J. L., Cheng, B. S., Chou, L. F., \& Chu, X. P. (2006). Authority and benevolence: Employees' responses to paternalistic leadership in China. In A. S. Tsui, Y. Bian, \& L. Cheng (Eds.), China's domestic private firms: Multidisciplinary perspectives on management and performance (pp. 230-260). New York, NY: Sharpe.

Gioia, D. A., \& Chittipeddi, K. (1991). Sensemaking and sensegiving in strategic change initiation. Strategic Management Journal, 12, 433-448.

Glynn, M. A., Kazanjian, R., \& Drazin, R. (2010). Fostering innovation in complex product development settings: The role of team member identity and interteam interdependence. Journal of Product Innovation Management, 27, 1082-1095.

Gong, Y., Huang, J. C., \& Farh, J. L. (2009). Employee learning orientation, transformational leadership, and employee creativity: The mediating role of employee creative self-efficacy. Academy of Management Journal, 52, 765-778.

Gumusluoglu, L., \& Ilsev, A. (2009). Transformational leadership, creativity and organizational innovation. Journal of Business Research, 62, 461-473.

Gupta, V., \& Singh, S. (2015). Leadership and creative performance behaviors in R\&D laboratories: Examining the mediating role of justice perceptions. Journal of Leadership \& Organizational Studies, 22, 21-36.

Hewstone, M., Rubin, M., \& Willis, H. (2002). Intergroup bias. Annual Review of Psychology, 53, 575-604.

Hirst, G., \& Mann, L. (2004). A model of R\&D leadership and team communication: The relationship with project performance. $R \& D$ Management, 34, 147-160.
Hirst, G., van Dick, R., \& van Knippenberg, D. (2009). A social identity perspective on leadership and employee creativity. Journal of Organizational Behavior, 30, 963-982.

Hoegl, M., Weinkauf, K., \& Gemuenden, H. G. (2004). Interteam coordination, project commitment, and teamwork in multiteam R\&D projects: A longitudinal study. Organization Science, 15, 38-55.

Hofstede, G. (1980). Culture's consequences: International differences in work-related values. Beverly Hills, CA: Sage.

Hogg, M. A., van Knippenberg, D., \& Rast, D. E. (2012). Intergroup leadership in organizations: Leading across group and organizational boundaries. Academy of Management Review, 37, 232-255.

Hülsheger, U. R., Anderson, N., \& Salgado, J. F. (2009). Teamlevel predictors of innovation at work: A comprehensive meta-analysis spanning three decades of research. Journal of Applied Psychology, 94, 1128-1145.

James, L. R., Demaree, R. G., \& Wolf, G. (1993). rwg: An assessment of within-group interrater agreement. Journal of Applied Psychology, 78, 306-309.

Janis, I. L. (1982). Groupthink: Psychological studies of policy decisions and fiascoes (2nd ed.). Boston, MA: Houghton Mifflin.

Janssen, O. (2000). Job demands, perceptions of effort-reward fairness and innovative work behavior. Journal of Occupational and Organizational Psychology, 73, 287-302.

Jöreskog, K. G., \& Sörbom, D. (1993). LISREL 8: Structural equation modeling with the SIMPLIS command language. Chicago, IL: Scientific Software International.

Kane, A. A., Argote, L., \& Levine, J. M. (2005). Knowledge transfer between groups via personnel rotation: Effects of social identity and knowledge quality. Organizational Behavior and Human Decision Processes, 96, 56-71.

Karakas, F., \& Sarigollu, E. (2012). Benevolent leadership: Conceptualization and construct development. Journal of Business Ethics, 108, 537-553.

Karakitapoğlu-Aygün, Z., \& Gumusluoglu, L. (2013a). A reconceptualization of transformational leadership in the Turkish context. Turkish Journal of Psychology, 28, 105-124.

Karakitapoğlu-Aygün, Z., \& Gumusluoglu, L. (2013b). The bright and dark sides of leadership: Transformational vs. non-transformational leadership in a non-Western context. Leadership, 9, 107-133.

Keller, R. T. (2006). Transformational leadership, initiating structure, and substitutes for leadership: A longitudinal study of research and development project team performance. Journal of Applied Psychology, 91, 202-210.

Konovsky, M. A., \& Pugh, S. D. (1994). Citizenship behavior and social exchange. Academy of Management Journal, 37, 656669.

Li, G., Shang, Y, Liu, H., \& Xi, Y. (2014). Differentiated transformational leadership and knowledge sharing: A cross-level investigation. European Management Journal, 32, 554-563.

Luthans, F., \& Avolio, B. J. (2003). Authentic leadership: A positive developmental approach. In K. S. Cameron, J. E. Dutton, \& R. E. Quinn (Eds.), Positive organizational scholarship (pp. 241-261). San Francisco, CA: Barrett-Koehler.

Maitlis, S. (2005). The social process of organizational sensemaking. Academy of Management Journal, 48, 21-49. 
Markham, S. E. (2012). The evolution of organizations and leadership from the ancient world to modernity: A multilevel approach to organizational science and leadership (OSL). Leadership Quarterly, 23, 1134-1151.

Markham, S. E., \& Halverson, R. R. (2002). Within- and betweenentity analyses in multilevel research: A leadership example using single level analyses and boundary conditions (MRA). Leadership Quarterly, 13, 35-52.

Markham, S. E., \& McKee, G. H. (1995). Group absence behavior and standards: A multilevel analysis. Academy of Management Journal, 38, 1174-1190.

Markham, S. E., Smith, J. W., Markham, I. S., \& Braekkan, K. F. (2014). A new approach to analyzing the Achilles' heel of multisource feedback programs: Can we really trust ratings of leaders at the group level of analysis? Leadership Quarterly, $25,1120-1142$.

Markham, S. K., \& Lee, H. (2014). Marriage and family therapy in NPD teams: Effects of we-ness on knowledge sharing and product performance. Journal of Product Innovation Management, 31, 1291-1311.

Mascitelli, R. (2000). From experience: Harnessing tacit knowledge to achieve breakthrough innovation. Journal of Product Innovation Management, 17, 179-193.

Mumford, M. D., \& Gustafson, S. B. (1988). Creativity syndrome: Integration, application, and innovation. Psychological Bulletin, 103, 27-43.

Mumford, M. D., Scott, G. M., Gaddis, B., \& Strange, J. M. (2002). Leading creative people: Orchestrating expertise and relationships. Leadership Quarterly, 13, 705-750.

Norrgren, F., \& Schaller, J. (1999). Leadership style: Its impact on cross-functional product development. Journal of Product Innovation Management, 16, 377-384.

Pellegrini, E. K., \& Scandura, T. A. (2006). Leader-member exchange (LMX), paternalism and delegation in the Turkish business culture: An empirical investigation. Journal of International Business Studies, 37, 264-279.

Pellegrini, E. K., \& Scandura, T. A. (2008). Paternalistic leadership: A review and agenda for future research. Journal of Management, 4, 566-593.

Pellegrini, E. K., Scandura, T. A., \& Jayaraman, V. (2010). Cross-cultural generalizability of paternalistic leadership: An expansion of leader-member exchange theory. Group \& Organization Management, 35, 391-420.

Pinto, M. B., Pinto, J. K., \& Prescott, J. E. (1993). Antecedents and consequences of project team cross-functional cooperation. Management Science, 39, 1281-1298.

Preacher, K. J., \& Hayes, A. F. (2008). Asymptotic and resampling strategies for assessing and comparing indirect effects in multiple mediator models. Behavior Research Methods, 40, 879-891.

Ravasi, D., \& Schultz, M. (2006). Responding to organizational identity threats: Exploring the role of organizational culture. Academy of Management Journal, 49, 433-458.

Richter, A. W., Scully, J., \& West, M. A. (2005). Intergroup conflict and intergroup effectiveness in organizations: Theory and scale development. European Journal of Work and Organizational Psychology, 14, 177-203.

Richter, A. W., West, M. A., van Dick, R., \& Dawson, J. F. (2006). Boundary spanners' identification, intergroup contact, and effective intergroup relations. Academy of Management Journal, 49, 1252-1269.

Sarros, J. C., Cooper, B. K., \& Santora, J. C. (2008). Building a climate for innovation through transformational leadership and organizational culture. Journal of Leadership \& Organizational Studies, 15, 145-158.

Schriesheim, C. A., Cogliser, C. C., \& Neider, N. L. (1995). Is it "trustworthy"? A multiple-levels-of-analysis reexamination of an Ohio state leadership study, with implications for future research. Leadership Quarterly, 6, 111-145.

Scott, S. G., \& Bruce, R. A. (1994). Determinants of innovative behavior: A path model of individual innovation in the workplace. Academy of Management Journal, 37, 580-607.

Shamir, B., Zakay, E., Breinin, E., \& Popper, M. (2000). Leadership and social identification in military units. Journal of Applied Social Psychology, 30, 612-640.

Sherif, M. (1966). In common predicament: Social psychology of intergroup conflict and cooperation. Boston, MA: Houghton Mifflin.

Shrout, P. E., \& Bolger, N. (2002). Mediation in experimental and nonexperimental studies: New procedures and recommendations. Psychological Methods, 7, 422-445.

Slater, L. (2005). Leadership for collaboration: An affective process. International Journal of Leadership in Education, 8, 321-333.

Somech, A. (2006). The effects of leadership style and team process on performance and innovation in functionally heterogeneous teams. Journal of Management, 32, 132-157.

Somech, A., \& Drach-Zahavy, A. (2013). Translating team creativity to innovation implementation. The role of team composition and climate for innovation. Journal of Management, 39, 684-708.

Sözen, S., \& Shaw, I. (2003). Turkey and the European Union: Modernizing a traditional state? Social Policy \& Administration, 37, 108-120.

Taggar, S. (2002). Individual creativity and group ability to utilize individual creative resources: A multilevel model. Academy of Management Journal, 45, 315-330.

Tajfel, H., \& Turner, J. C. (1986). The social identity theory of intergroup behavior. In S. Worchel \& W. G. Austin (Eds.), Psychology of intergroup relations (pp. 7-24). Chicago, IL: Nelson-Hall.

Umphress, E. E., Bingham, J. B., \& Mitchell, M. S. (2010). Unethical behavior in the name of the company: The moderating effect of organizational identification and positive reciprocity beliefs on unethical pro-organizational behavior. Journal of Applied Psychology, 95, 769-780.

van Knippenberg, B., van Knippenberg, D., De Cremer, D., \& Hogg, M. A. (2004). Leadership, self, and identity: A review and research agenda. Leadership Quarterly, 15, 825-856.

van Knippenberg, D. (2000). Work motivation and performance: A social identity perspective. Applied Psychology: An International Review, 49, 357-371.

Waldman, D. A., \& Atwater, L. E. (1994). The nature of effective leadership and championing processes at different levels in an R\&D hierarchy. Journal of High Technology Management Research, 5, 233-245.

Wang, A. C., \& Cheng, B. S. (2010). When does benevolent leadership lead to creativity? The moderating role of creative role identity and job autonomy. Journal of Organizational Behavior, 31, 106-121. 
West, M. A. (2002). Sparkling fountains or stagnant ponds: An integrative model of creativity and innovation implementation in work groups. Applied Psychology: An International Review, 51, 355-424.

West, M. A., \& Farr, J. L. (1989). Innovation at work: Psychological perspectives. Social Behavior, 4, 15-30.

Zhao, X., Lynch, J. G., \& Chen, Q. (2010). Reconsidering Baron and Kenny: Myths and truths about mediation analysis. Journal of Consumer Research, 37, 197-206.

\section{Author Biographies}

Lale Gumusluoglu is an assistant professor at Faculty of Business Administration at Bilkent University. Her research interests include leadership, knowledge workers, individual and team-level innovation \& creativity, commitment and justice. She has published in journals such as Journal of Product Innovation Management, Journal of Business Research, Leadership and European Management Review.
Zahide Karakitapoglu-Aygün is an associate professor at Faculty of Business Administration at Bilkent University. Her research interests include commitment, transformational leadership, paternalistic leadership, organizational justice, team innovation and team processes. She has published in several journals such as Journal of Cross-Cultural Psychology, Personality and Social Psychology Bulletin, Leadership, Journal of Business Ethics, European Journal of Social Psychology, Journal of Social Psychology and Journal of Business Research.

Terri A. Scandura is a professor of Management in the School of Business Administration at the University of Miami. Her research interests include paternalistic leadership, leader-member exchange, mentoring, and applied research methods. She has published in several journals such as the Academy of Management Journal, the Journal of Applied Psychology, the Journal of International Business Studies, the Journal of Management, Organizational Research Methods, and the Journal of Organizational Behavior. 